\title{
Assessment of Quality Of Life and Demographic Characteristics among End Stage Renal Disease Hemodialysis Patients at the National Ribat University Hospital and Ibn Sina Specialized Hospital (July-2017)
}

\author{
Elmalik AB ${ }^{1}$, Ali IA ${ }^{2 *}$, Elawad $\mathrm{ME}^{3}$, Helali $\mathrm{MAH}^{3}$ and Alsayed $\mathrm{AHY}^{3}$ \\ ${ }^{1}$ Faculty of Medicine, Omdurman Islamic University, Sudan \\ ${ }^{2}$ Department of Physiology, Faculty of Medicine, The National Ribat University, Sudan \\ ${ }^{3}$ Faculty of Medicine, The National Ribat University, Sudan
}

*Corresponding author: Ibrahim Abdelrhim Ali, Assistant Professor of Medical Physiology, Department of Physiology, Faculty of Medicine, The National Ribat University, Sudan; Email: hemamedicine@gmail.com

\section{Research Article}

Volume 5 Issue 2

Received Date: July 13, 2020

Published Date: August 19, 2020

DOI: $10.23880 /$ oajun-16000180

\section{Abstract}

Introduction: End-stage renal disease (ESRD) disease is a public health problem worldwide that is highly associated with medical, social and psychological disorders particularly in those treated with Hemodialysis. It leads to loss in mobility, exercise capacity, and self-assessed physical function, and is further associated with reduced ability to work and function in daily life.

Objectives: This study was aimed to assess the quality of life (QOL) among Hemodialysis patients admitted at the National Ribat University Hospital and Ibn Sina Specialized Hospital during June-October 2017.

Methodology: A cross-sectional prospective study was conducted at Hemodialysis units of National Ribat University Hospital and Ibn Sina Specialized Hospital in 120 patients undergoing regular Hemodialysis for more than six months. The WHO quality of life questionnaire was used. Verbal and written consent was taken from any patient after explaining the purpose of the study. Statistical analysis was performed using SPSS version 25.0.

Results: One hundred-twenty patients were enrolled which included forty males (66.7\%) and twenty (33.3\%) females. The assessment of quality of life shows only $10 \%$ have good QOL, $46.6 \%$ have moderate QOL, $40 \%$ have poor QOL and $3.3 \%$ have very poor QOL.

Conclusion: Generally person with ESRD are more likely to have reduced quality of life and poor overall health in compared with subjects with normal renal function. This findings suggest that ESRD maintained on prolonged Hemodialysis is associated with reduced relatively decreased QOL and long term bad outcomes affecting subject's overall aspects of health.

Keywords: ESRD; Quality of Life; Renal Failure; Dialysis

Abbreviations: ESRD: End-Stage Renal Disease; QOL: Quality of Life; IQLA: Quality of Life Assessment.

\section{Introduction}

Quality of life is the ability of an individual to perform his or her physical, psychological, and social functions normally. We also note in its definition that it is the measure of the health of the individual that results in his productivity, then the reconstruction of his environment [1]. There are many contributions to assess the quality of life in different countries. One of the most important is the International Quality of Life Assessment (IQLA) project, which aims to test the consequences for physical and mental health. In addition, 
Health facilities indicators include SF-36 standards for use in feasibility studies [2].

This is at the general level, but at the private one, society can be divided into groups based on the degree of burden on each group. Each is examined in detail for a more visible view. End-stage renal disease (ESRD) patients one of the most important of these overburdened groups. They are suffering from debilitating symptoms that include almost every system in the body [3]. In particular, a study in Hong Kong found that quality of life was low in ESRD patients, whether on kidney dialysis or palliative care [4]. The results in a study of 144 patients undergoing various types of kidney replacement treatment showed that $49 \%$ were unemployed due to physical and functional disabilities resulting from ESRD [5]. These percentages, if we omit them, we expect that they will be increased significantly in a short period of time. Especially as ESRD patients are significantly doubled 4 times in number [6]. Not only is it the loss of the workforce, but it goes beyond it to reflect its negative effects on patient family, society and the country's economy.

To avoid all of these consequences, all countries must be critical, and much research is being done and is contributing to the resolution of the problem. The aims of this study was to assess the quality of life in Hemodialysis patients at the National Ribat University Hospital and IbnSina Hospital using WHO quality of Life questionnaire Brief to serve as a solid base for rehabilitation programs and their design in accordance with functional requirements.

\section{Methods}

A descriptive hospital-based study, a convenient sample of 120 ESRD patients undergoing regular Hemodialysis was recruited from two dialysis centres of the National Ribat University Hospital and Ibn Sina specialized hospital at Khartoum city, Republic of Sudan. Participants were included if their ages between 18 and 85 years old, had a diagnosis of ESRD on more than 6 months of regular Hemodialysis.

Measurement of Patients general and disease-specific health related quality of life was examined by WHO quality of life brief questionnaire, which was developed by the WHOQOL Group with fifteen international field centers, simultaneously, in an attempt to develop a quality of life assessment that would be applicable cross-culturally. Other questionnaire was done for assessment of the presence of other medical comorbidities.

\section{Data Analysis}

Statistical analysis was performed using SPSS version 25.0. Proportions of the studied groups were expressed in percentages and means were used to describe the studied variables, $P$ value $\leq, 05$ was considered significant.

Ethical Considerations: Verbal and written consent from any patient after explaining the purpose of the study. Ethical approvals were taken from the National Ribat University Hospital and Ibn Sina specialized hospital.

\section{Results}

120 patients included in the study, $60 \%$ of them from Ibn sina specialized hospital and $40 \%$ from the National Ribat University hospital. The gender distribution figures showed male's dominance by $66.7 \%$ and females measuring $33.3 \%$ of sample population (Figure 1).

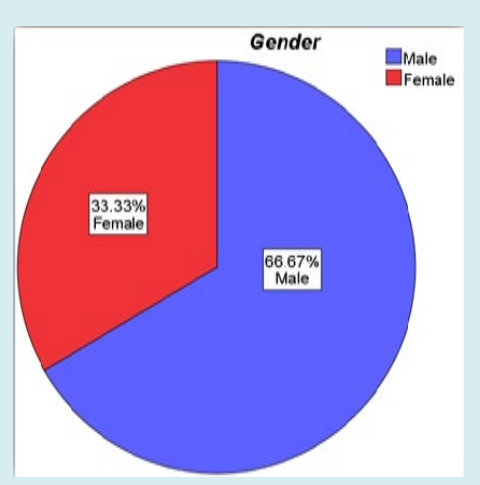

Figure 1: Gender Distribution among Hemodialysis Patients in National Ribat University Hospital and Ibn Sena Specialized Hospital in June, 2017. N=120.

$51.6 \%$ of the patients were between 41-60 years old, $31 \%$ between $18-40$ year old and $16.6 \%$ between $61-85$ years old (Figure 2).

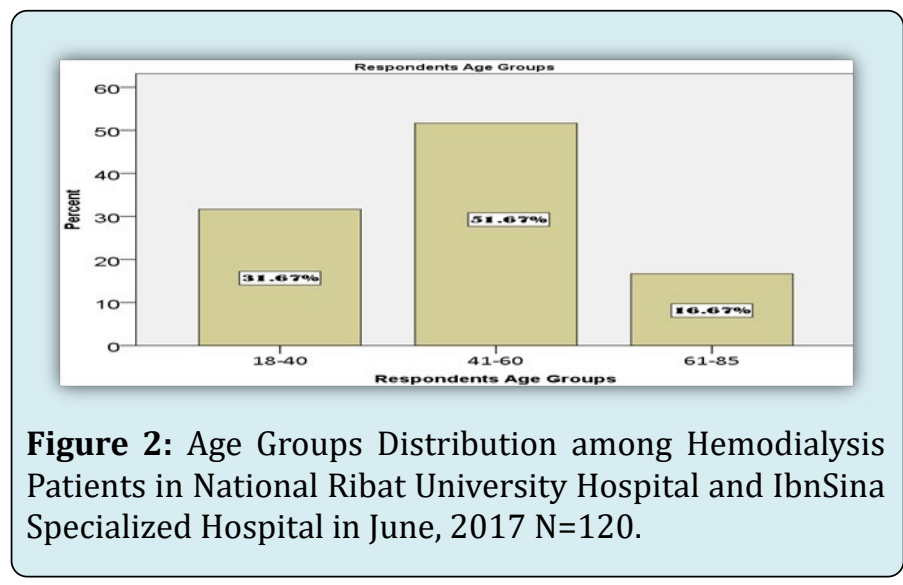

Educational level among respondents showed that the patients were school level (primary or secondary) in 63.3\%, 


\section{Open Access Journal of Urology \& Nephrology}

while $23.3 \%$ were university graduates or above and the rest was illiterate. Regarding the occupations of the participants, $46.6 \%$ of them were Jobless, while $41.6 \%$ works in different jobs (Figure 3).

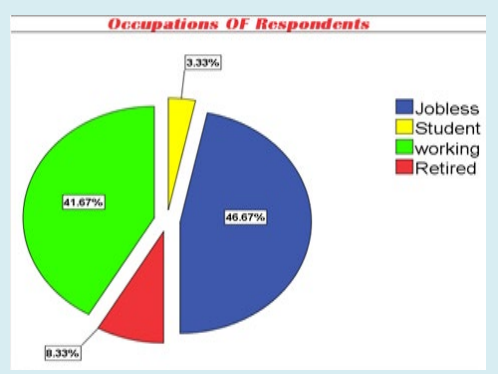

Figure 3: Occupations of The participants of Hemodialysis Patients in National Ribat University Hospital and Ibn Sina Specialized Hospital In July, 2017.

Regarding the marital status of sample population , $76.67 \%$ were married, while $16.67 \%$ were singles, $3.33 \%$ either divorced or separated and the rest of sample were widows 3.33\% (Figure 4).

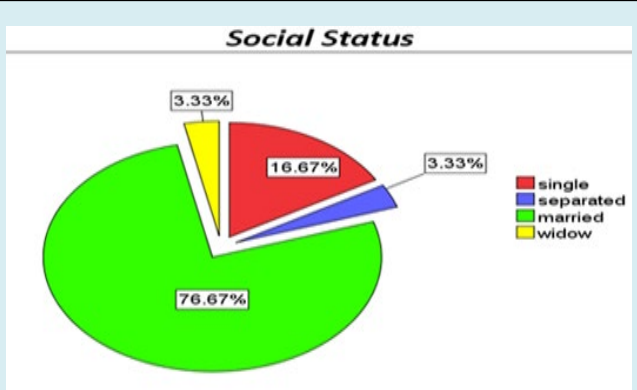

Figure 4: Marital status of the participants of Hemodialysis Patients in National Ribat University Hospital and IbnSina Specialized Hospital In July, 2017.

In the other side, the prevalence of Diabetes Mellitus among participants was found to be $16 \%$. However Hypertension was predominant by $60 \%$ among respondent sample, while $11.7 \%$ of total sample have both DM and HTN. Also $5 \%$ was found to be had positive history of chronic liver diseases (Table 1).

\begin{tabular}{|c|c|}
\hline Percent & Chronic Diseases \\
\hline $60 \%$ & Hypertension \\
\hline $16 \%$ & Diabetes Mellitus \\
\hline $5 \%$ & Chronic liver disease \\
\hline $11.70 \%$ & Both DM and HTN \\
\hline
\end{tabular}

Table 1: Presence of chronic diseases in ESRD Hemodialysis Patients in the studied sample.
Assessment of quality of life shows that, $46.6 \%$ of participant's have Moderate Quality of Life (81-107 score), and $40 \%$ have POOR QUALITY OF LIFE (54-80 SCORE) (Figure 5).

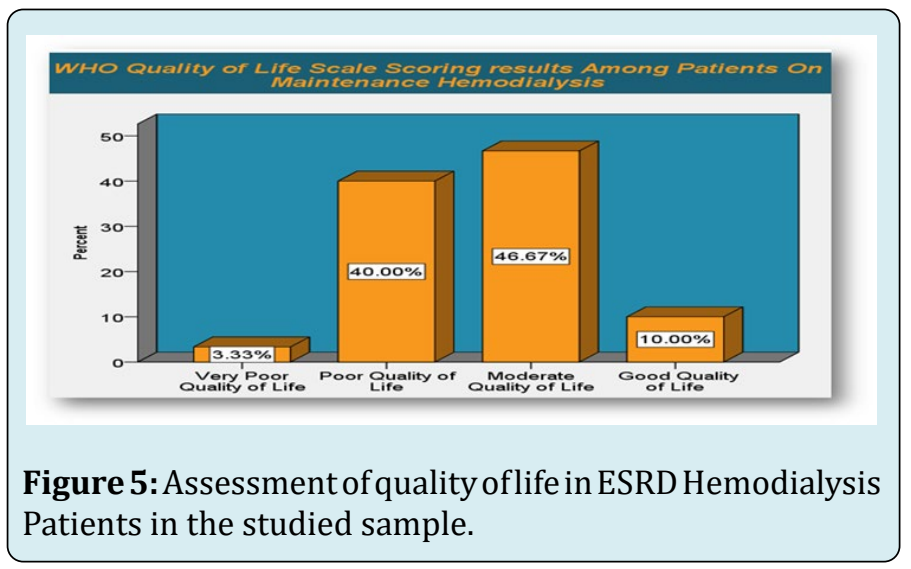

\section{Discussion}

In the studied sample of 120 hemodialysis patients it's showed that generally person with ESRD are more likely to have reduced quality of life and poor overall health in our study compared with subjects with normal renal function. Our findings suggest that ESRD maintained on prolonged Hemodialysis is associated with reduced relatively decreased QOL and long term bad outcomes affecting subject's overall aspects of health [7].

Physical health is one of the factors on which quality of life is assessed, and we have noticed that the majority of the sample was males at a ratio of $2: 1$. These are subject to a wide range of pressures in their daily activities, especially in a low-income country. 60\% suffer from hypertension, which is known to be a debilitating disease. Also, a large slice of the sample is between the ages of 18-40 and 41-60. These categories represent the period when a person is doing a great physical effort compared to the rest of his or her life and are exposed to the surrounding environment with its various elements that form one of the assessment process pillars. In addition, the majority was insufficiently educated, and all of the above had negative effects on the quality of life. A very high proportion of the sample population was married, which means they have a responsibility to face the burdens of the life and the environment [8]. On the other hand, it can be said that marriage helps in psychological stability, which positively affects another factor of life quality evaluation, namely mental health.

At the occupation level, the proportions of the employees and the non-employees were close. This convergence can lead us to two opposite directions. The first is unemployment which may affect the individual's psychology negatively and 


\section{Open Access Journal of Urology \& Nephrology}

give him a sense that he is a burden on his society, which weakens psychological health. The second trend is that the worker has a greater chance to face job and environmental conditions, which means influencing physical health. Both directions lead to poor quality of life.

This study covered the overall impact of several factors on the quality of life. We hope future research will address each individual factor to identify the most likely contributor so that it can be handled in an organized scientific way.

\section{Conclusion and Recommendations}

A significant proportion of the ESRD population is classified as poor quality of life individuals. However, we can consider ESRD as a risk factor for low quality of life. Developing a more supported and good quality physical and mental services provided to renal dialysis population and special protocols for regular 6 Monthly screening of quality of life are recommended.

\section{References}

1. Valderrábano F, Jofre R, López-Gómez JM (2001) Quality of life in end-stage renal disease patients. American Journal of Kidney Diseases 38(3): 443-464.

2. Aaronson NK, Acquadro C, Alonso J, Apolone G, Bucquet $D$, et al. (1992) International quality of life assessment
(IQOLA) project. Qual Life Res 1(5): 349-351.

3. Murtagh FE, Addington-Hall J, Higginson IJ (2007) The prevalence of symptoms in end-stage renal disease: a systematic review. Adv Chronic Kidney Dis 14(1): 82-99.

4. Yong DS, Kwok AO, Wong DM, Suen MH, Chen WT, et al. (2009) Symptom burden and quality of life in end-stage renal disease: a study of 179 patients on dialysis and palliative care. Palliat Med 23(2): 111-119.

5. Blake C, Codd MB, Cassidy A, O'Meara YM (2000) Physical function, employment and quality of life in end-stage renal disease. J Nephrol 13(2): 142-149.

6. Levey AS, Coresh J, Bolton K, Culleton B, Harvey KS, et al. (2002) K/DOQI clinical practice guidelines for chronic kidney disease: evaluation, classification, and stratification. Am J Kidney Dis 39(1): 1-266.

7. Watnick S, Wang PL, Demadura T, Ganzini L (2005) Validation of 2 depression screening tools in dialysis patients. Am J Kidney Dis 46(5): 919-924.

8. Loosman WL, Siegert CEH, Korzec A, Honig A (2010) Validity of the Hospital Anxiety and Depression Scale and the Beck Depression Inventory for use in end-stage renal disease patients. Br J Clin Psychol 49(Pt 4): 507516.

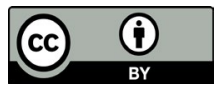

